\title{
Clothing Disposal Behavior of Taiwanese Consumers with Respect to Environmental Protection and Sustainability
}

\author{
Chih-Chun Lai and Ching-Erh Chang * \\ Graduate Institute of Design Science, Tatung University, Taipei City 104, Taiwan; lai@ttu.edu.tw \\ * Correspondence: cce3056@ms34.hinet.net
}

Received: 9 October 2020; Accepted: 9 November 2020; Published: 13 November 2020

\begin{abstract}
Large quantities of clothing are routinely discarded, ending up in landfills that contribute to the environmental crisis; hence, it is worthwhile investigating how to dispose of this waste in a sustainable way. This study considered environmental values and prosocial behavior from behaviorism theory. The aim was to set up an environmental protection model for the sustainable disposal of consumer clothing. A structural equation modeling analysis of 407 undergraduate and postgraduate consumer data in Taiwan revealed that consumers' choice to donate clothing was influenced by environmental values and prosocial behaviors. Clothing resale was influenced by the factor of prosocial behavior. However, prosocial consumers used other disposal patterns instead of resale. Clothing reuse was not influenced by either environmental values or prosocial behavior. The behaviorism theory model is effective in analyzing the factors influencing sustainable clothing disposal. To face clothing waste issues, one can intensify traditional values of industriousness and thriftiness, and of compassion and sympathy to others, to accelerate the promotion of the sustainable disposal of clothing.
\end{abstract}

Keywords: environmental values; prosocial behavior; sustainable; clothing disposal behavior

\section{Introduction}

In more difficult times, people continually reused their unwanted clothes; nowadays in Taiwan, people's unwanted clothes are mostly placed in their closet or into recycle bins or recycled by a recycle truck [1]. Clothes which are in good condition after recycling and classifying can enter into secondhand clothing markets. However, consumers prefer newly manufactured clothes to secondhand clothes, and they only rent clothes used in weddings, cheerleading or drama at present. This has inhibited the growth of secondhand clothing markets up to now. Concerning disposition, consumers who directly recycle their unwanted clothes regard it as not only the easiest, environmentally friendly option but also as reflecting compassion.

For students who have received environmental education, it is worthwhile to discuss whether they build environmental values, and whether students learn to avoid excessive unwanted clothing and dispose of clothing appropriately, due to considerate and service-minded attitudes. Furthermore, it is important to develop and integrate environmental values into one's life during university, as undergraduates have sufficient cognitive abilities to make decisions and execute prosocial behaviors [2]. Now, consumers' clothing disposal habits can be predicted using behaviorism theory. The theory claims that particular stimuli can lead an individual to have a specific reaction [3]. An example of a stimulus is a belief in environmental values; care for the environment and a desire to help others can promote responsible behaviors regarding the environment. Previous research indicates that these stimuli do actually influence behavior [4,5]. The emphasis of sustainable clothing disposal 
is to reduce the purchase of newly manufactured clothes so people can co-exist in and share the environment. The purpose is to dispose of clothes sustainably in ways that can both express care of society and the environment and promote mutual benefits, such as resale, donation and reuse.

This study consequently places emphasis on regarding whether environmental values and prosocial behaviors significantly influence clothing disposal, and more importantly which factor influences consumers in how to dispose of their clothing. The aim of this study is to take consumers' views into account and discuss causal relationships, to link clothing disposal patterns with environmental values and prosocial behaviors on the basis of the behaviorism theory, to set up a hypothetical model of consumer clothing disposal behavior and to explain the influential factor of consumer clothing disposal that promotes sustainability by reducing clothing being discarded. Results can become a reference for further discussion of different cultures and different generations of consumers.

\section{Literature Review}

\subsection{The Environmental Crisis of the Clothing Industry}

"Fast fashion" as a trend has been widely criticized for depleting environmental resources and contributing to the destruction of our environment [6]. Given quick-turnaround products and including online shopping, clothing has become a "discard-style product," cheaply made out of poor materials, in Taiwan. According to a 2016 investigation by Greenpeace concerning consumer shopping habits in Taiwan, on average, 9.9 pieces of clothing every minute every year are discarded by people aged 20-45 [1]. Some of this clothing is placed in recycling bins and the rest is dumped into garbage cans. Further, the amount of greenhouse gas emission is continuously increasing; excessive emission of greenhouse gas causes pollution and worsens the environment [7]. Moreover, discard-style products have further exacerbated environmental damage. Clothing sustainability has increasingly received more attention these past few years. Secondhand clothing stores still advertise, revealing that the number of people who accept secondhand merchandise is increasing gradually in Taiwan.

\subsection{Sustainable Clothing Disposal Behavior}

In order to promote economic and social advancement in ways that avoid environmental degradation, over-exploitation or pollution, the World Commission on Environment and Development highlighted sustainability in 1987 [8]. It is important for consumers to be introspective and to carry out sustainable waste disposal of clothing in the face of the environmental crisis. Regarding sustainable clothing disposal, a survey of 232 consumers found that family norms, the environment and the economy influenced consumers' resale, donation or reuse of clothing [9]. Further research found that out of 488 consumers, those who recycled clothing mainly donated it to charity [10]. A different study of 410 consumers found that donation, resale, swap and take-back programs were the main disposal methods [11]. This study integrates and discusses multiple commonly used disposal methods-including resale, donation and reuse-from the customer perspective.

\subsection{Behaviorism Theory}

Behaviorism theory originates from the early 20th century. It claims that behavior is determined by the environment. According to behaviorism, behavior is provoked by a stimulus, which can be any object or event that elicits a sensory or behavioral response in an individual, including some outcomes, values or feelings, in an individual's life history [12]. Watson's "reductionism" hypothesized that individuals react to outside influences [3] and respond with a behavior; however, most behaviors are introspective, and behavior can also be influenced by consideration of possible future results [13]. When a consumer receives environmental crisis information related to excess clothing, the information forms a stimulus that leads the individual to make a response. A consumer's beliefs and values in environmental protection, past practical experiences in helping others, introspection, association and values in minimizing the waste of objects, environmental quality and relationship with others all 
together affect the consumer's follow-up clothing disposal behaviors by taking responsibility for the environment. Research indicates that individual values and prosocial behavior promote sustainable environmental protection behavior [12,14].

\subsection{Environmental Values}

Concerning values, "A value is a belief that something is good and worthwhile. It defines what is worth having and worth striving for [15]." According to sociology, values provide behavioral goals for members of societies, ensuring consistent human interaction. Values further help people to adjust their behavior in different situations [16]. They lend stability to the social order, which is critical to public welfare, and provide general norms for social behavior. They also influence one's attitude about one's surroundings and behavioral tendencies.

However, the prosperity of developed countries around the world has threatened the living environment of human beings in that natural resources are being depleted and large amounts of waste are being returned to the environment [17]. These circumstances cannot help but remind one of traditional Chinese philosophy, which emphasizes the "oneness of heaven and humanity." This reveals that nature is definitely the origin of life for human beings. The Chinese philosopher Cheng Hao (1032-1085) put forward a thought that humans possess a kindheartedness that can be extended from "love the people" to "love all things." Thus, humanity and nature are a closely linked and organic whole that is constituted on the basis of Confucianism's directive of "love the people." Applying this thought to the contemporary environment, people should accommodate themselves to the laws of nature, respect and care for nature and strive for harmonious co-existence between humans and nature [18]. A research study of 468 undergraduates revealed that environmental attitudes had a strong influence on the disposal patterns of clothing [19]. Environmental values hence encompass an individual's sustainable disposal in articles, which is an idea that is beneficial to the natural ecology environment.

Concerning environmental values, one research study revealed that the environment is one of the main reasons for sustainable textile disposal. [20]. A five-person qualitative study found that secondhand clothes can be kept not just for longevity but also to raise product value through swaps, repair, upgrade, redesign or craft skills such as embroidery or dyeing [21]. This gives old products a longer life cycle and prevents the further consumption of environmental resources from the production of new clothes [22]. Research has found that undergraduate resale behaviors were related to economic issues [9]; the results were the same as previous studies, finding that undergraduates also resell their clothing because of the economy [19]. However, whether resale leads to other new influence factors after a number of years is a question worth studying. A qualitative study of 24 persons in Sweden indicated that both reuse and resale are not the most common options for handling home textiles for member buyers of IKEA products, especially textile values, which participants do not take notice of. Participants believed that home textile products are cheap and have poor quality and cannot be reused or donated, and so they are discarded [20]. A subsequent study on clothing donation found that consumers' environmental consciousness significantly influenced their behavior of donating excess clothes [23]. A study of 232 undergraduates found that undergraduate donation behaviors were relative to environmental issues [9]. Today, environmental protection is a common human value that can be implemented in daily life. Individuals could practice environmental awareness and values through the sustainable disposal of clothes, thereby promoting overall environmental well-being. Thus, this study proposes the following hypotheses:

Hypothesis 1 (H1). Environmental values significantly influence clothing resale.

Hypothesis 2 (H2). Environmental values significantly influence clothing donation.

Hypothesis 3 (H3). Environmental values significantly influence clothing reuse. 


\subsection{Prosocial Behavior}

Regarding prosocial behavior in Chinese society, Confucianism advocated that kindheartedness is the root of humanity, human nature is basically good and humans have basic and innate natural characteristics from birth, especially compassion or sympathy for others. Furthermore, one should love oneself first, then love one's own flesh and blood and then love all people. In addition, Confucianism also advocated "do not do to others what you don't want to be done to you," which is a guiding principle, and for conducting oneself with "responsibility" for others as one of the basic thoughts. Consequently, the prosocial behavior of Confucianism is an extensive love for others.

As for Western society, from the perspective of social psychology, prosocial behavior of an individual eventually becomes an internalized value along with the realization of social norms and the progress of ageing. Moreover, prosocial behavior is aimed at promoting the common good and is a part of daily life as well. It can help and improve the situation of people and finally improve the co-existent and shared environment [24]. From the perspective of social cognition, the individual is based on sympathy, comprehending his own social role and sense of responsibility, which can initiate a positive response, reduce personal concerns, increase understanding of others in need and transform prosocial cognition into prosocial behaviors [25]. In short, a prosocial individual will "deny himself and be zealous in helping others [2]," engaging in behaviors such as care, help and understanding.

Sustainable disposal of clothing-such as resale, donation and reuse-displays care and a responsible attitude towards society and the environment, and it is relevant to everyone. Many studies have shown that an awareness of the need for environmental protection is constantly growing among consumers and reflected in their daily activities [26,27]. Instead of being immediately discarded, everyday items should be reused after usage. Traditional Chinese society emphasized diligence and thriftiness and advocated cultivating virtues that would enable one to maintain a moral character, manage a household and run a country. A survey of 425 adults revealed that prosocial behavior is associated with the tendency to reuse clothing [28]. The study found that $64.3 \%$ of consumers used traditional services such as tailoring [29]. Another pattern of reuse is to upgrade one's clothing, or to disassemble parts of clothes and use different materials, colors, shapes or silhouettes to replace damaged parts and therefore renew the garments [30]. Clothing redesign is another one of the common disposal patterns: many purchasers prefer redesigning old clothing to buying new clothing [31]. One study found that prosocial behavior is a secondary reason for consumers to sustainably dispose of their textiles [20].

Concerning donation, one study in North Korea indicated that a philanthropic factor influenced 143 undergraduates' sustainable consumption behavior [32]. Another survey study $(n=981)$ in Germany found that compassion was positively correlated with the purchase intention on sustainable clothes [33]. Norum [34] tested U.S. female consumers and found that the most popular pattern of clothing disposal, at $64.54 \%$, was charitable donation, followed by resale to secondhand stores at $49.17 \%$. Koch and Domina's [35] study revealed that the common reason for making a donation was to help someone who was in need. Further, a study of 315 female consumers in South Africa indicated that their main method of disposal for unwanted apparel was donation, followed by reuse and lastly resale [36]. Research in Sweden has found that one of the most common options for handling home textiles is donation, as consumers are not interested in resale. One possible explanation is that consumers are unfamiliar with this option [20]. Nonetheless, the success of a resale experience is likely to increase consumers' willingness to conduct it. It is possible that the disposal of unwanted clothes is related to prosocial behaviors, such as help and compassion. Consumer's caring behaviors, willingness to help others and empathy influence their clothing disposal. Thus, the hypotheses are as follows:

Hypothesis 4 (H4). Prosocial behavior significantly influences clothing resale.

Hypothesis 5 (H5). Prosocial behavior significantly influences clothing donation. 
Hypothesis 6 (H6). Prosocial behavior significantly influences clothing reuse.

To face the environmental crisis, the only way to live sustainably is to change one's own consumption habits and to choose a lifestyle that minimizes impact on the environment and society [1]. This study was aimed at discarded clothes to discuss the influence of environmental values and prosocial behavior on methods for the disposal of clothing.

\section{Research Methods}

\subsection{Research Procedure}

This study mainly discusses environmental values and prosocial behaviors and whether they influence consumers' clothing disposal. The goal is to analyze environmental values and prosocial behaviors through the basis of the behaviorism theory. According to a literature review, the research procedure in this study runs as follows (Figure 1).

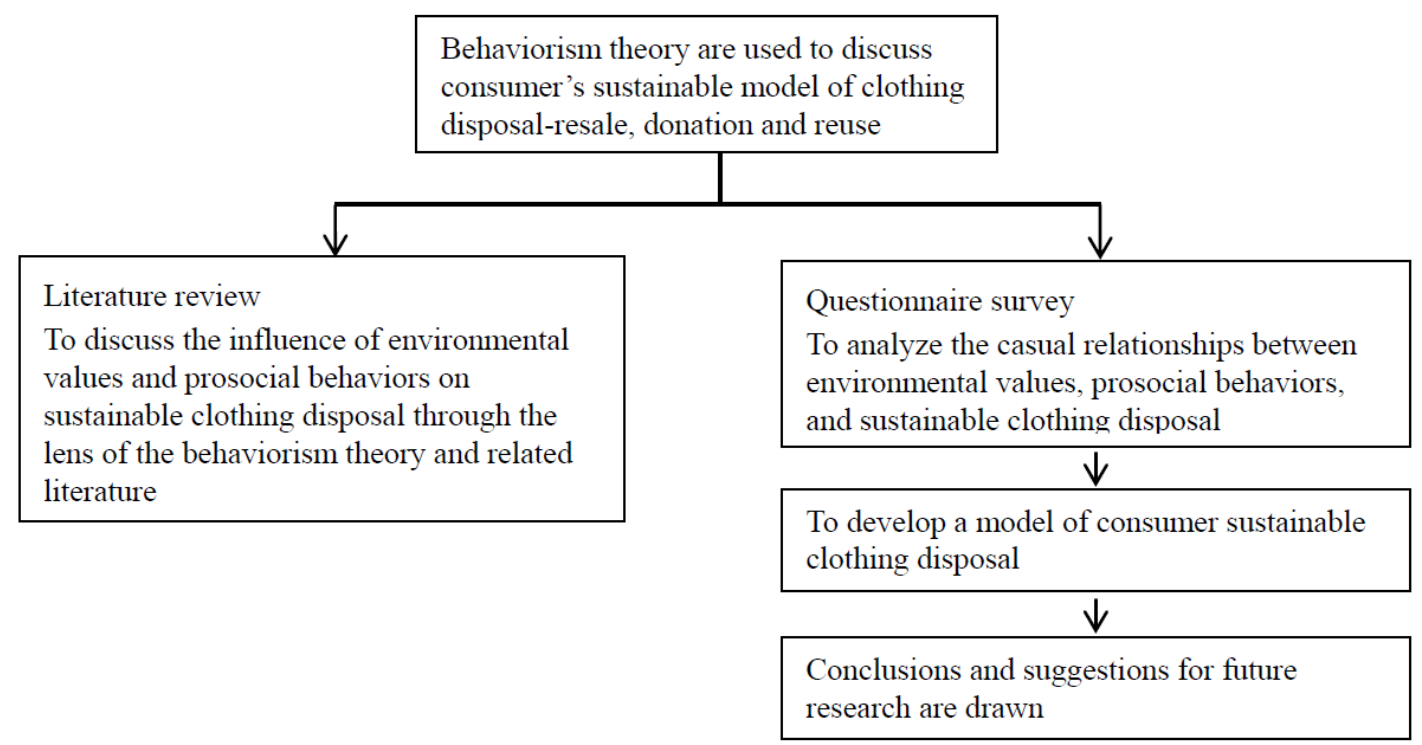

Figure 1. Research procedure.

First, this study analyzes the disposal patterns of clothing by consumers and discusses the influence of environmental values and prosocial behaviors on sustainable clothing disposal through the lens of the behaviorism theory and related literature. Second, this study discusses and investigates the causal relationships between environmental values, prosocial behaviors and sustainable clothing disposal—resale, donation, and reuse — through an online survey and develops a model of consumer sustainable clothing disposal. Finally, conclusions and suggestions for future research are drawn.

\subsection{Research Framework}

Clothing disposal influences the environment and is relevant to every person; this study aims to discuss the factors that influence consumers' choices regarding sustainable clothing disposal. According to behaviorism theory, which holds that stimuli induce reaction through introspection [13], sustainable clothing disposal behavior will not only be influenced by values (such as attitudes toward surroundings or behavioral tendencies) but also by prosocial behavior, such as reducing concern for oneself and demonstrating more understanding of others' needs. Hence, environmental values encompass an individual's sustainable disposal in articles, which is an idea that is beneficial to the natural ecology environment. A prosocial individual will "deny himself and be zealous in helping others [2]," engaging in behaviors. This study is based on behaviorism theory and links 
both environmental values and prosocial behavior, attempting to predict their influence on consumer clothing disposal.

\subsection{Instruments Development}

In this study, survey data included environmental values, prosocial behavior, sustainable clothing disposal behavior of consumers and demographic data. To help the participants understand the survey questions, researchers supplied them with a description taken from the literature review of environmental values, prosocial behavior and sustainable clothing disposal behavior. Environmental values imply that an individual makes sustainable clothing disposal choices based on their conviction of their benefit to the natural ecological environment. Prosocial behavior is any action intended for the good of others-an action that most often takes place at some cost to oneself-such as care, help and understanding. Sustainable clothing disposal behavior means that consumer's methods of disposal concerning unwanted clothing are activities such as resale, donation and reuse.

Furthermore, the final questionnaire consisted of 35 questions modified or designed from other studies to better meet the research purposes of the current study. The questionnaire was composed as follows: 9 questions modified or designed from Fu's [2] study pertained to environmental values, i.e., the "Value of Saving Energy and Reducing Carbon Emissions Scale"; 9 questions modified or designed from Carlo and Randall's [37] study addressed prosocial behavior, i.e., the "Prosocial Behavior Scale"; and 14 questions modified or designed from other studies pertained to sustainable clothing disposal behavior such as resale, donation and reuse. Among the last 14 questions, 3 questions modified or designed from Weber, Lynes and Young's [11] study focused on resale, i.e., the "Channels to Manage Unwanted Garments Scale"; 4 questions modified or designed from Bianchi and Birtwistle's [10] study focused on donation, i.e., the "Donating to Charity Disposal Behavior Scale"; and 7 questions modified or designed from Niinimäki and Hassi's [38] study focused on reuse, i.e., the "Consumers' Interest in Design Strategies Scale."

\subsection{Participants}

This study employed data from undergraduate and postgraduate students nationwide from 2 April to 21 May 2020, and data were gathered using a random online survey distributed through clothing-related groups on Facebook. This study used a survey of recording each subject's name, university name, department name or graduate school name in order to assure authenticity of the subject. Regarding sample size, according to Kerlinger and Lee [39] and Nunnally and Berstein [40], factor analysis requires a sample five to ten times the number of items on a scale. There are 35 questionnaire items in this study, so the effective sample must be at least 175 in order to conform to the requirement. The survey yielded 431 complete questionnaires, a $94.43 \%$ valid response rate. Basic demographic data about participants included gender, age and education. The majority of the participants were females due to the use of social media for recruitment.

\subsection{Data Analysis}

The participants in this study answered each question using a five-point Likert-type scale, ranging from 5 (strongly agree) to 1 (strongly disagree). The data collected were entered into a database and analyzed using the AMOS 22 statistical software package. In order to explore causal relationships among variables, this study executed a structural equation modeling and confirmatory factor analysis to examine the influence and predictability of each variable-environmental values and prosocial behavior-on the sustainable clothing disposal behavior of consumers. 


\section{Results and Discussion}

\subsection{Reliability and Validity}

This study analyzed data using structural equation modeling to examine the relationship between observed variables and latent variables and the causal relationships among variables. It examined the validity of the measure of the model through confirmatory factor analysis.

This study tested the degree of fit of the whole model to the observed data. In terms of environmental values, Table 1 shows that the GFI (Goodness of Fit Index), AGFI (Adjusted Goodness of Fit Index), IFI (Incremental Fit Index), NNFI (Non-Normed Fit Index) and CFI (Comparative Fit Index) values are $0.958,0.922,0.946,0.918$ and 0.946 , respectively, which are all considered a good fit. The RMSEA (Root Mean Square Error of Approximation) value is 0.078, which is acceptable [41]. Further, Bagozzi and Yi [42] maintained that the chi-square value should be less than 3 and that less than 5 was acceptable. The value of the chi-square/df ratio is 3.463, thus the result as acceptable. Consequently, Table 1 shows that the model fit of environmental values is acceptable. In terms of prosocial behavior, Table 1 shows that the GFI, AGFI, IFI, NNFI and CFI values are $0.965,0.935,0.971,0.956$ and 0.971 , respectively, which are all considered a good fit. The RMSEA value is 0.066 , which is acceptable. The value of the chi-square/df ratio is 2.787 , which conforms to the standard. Consequently, Table 1 shows that the model fit of prosocial behavior is good. In terms of sustainable clothing disposal behavior, Table 1 shows that the GFI, AGFI, IFI, NNFI and CFI values are $0.907,0.867,0.942,0.928$ and 0.942 , respectively, which are considered acceptable. The RMSEA value is 0.084 , which is slightly greater than 0.8 . The value of the chi-square/df ratio is 3.856 , which is acceptable. Consequently, Table 1 shows that the model fit of sustainable disposal behavior is acceptable.

Table 1. Summary of model fit for environmental values, prosocial behavior and sustainable clothing disposal.

\begin{tabular}{cccccccc}
\hline Variables & $\chi^{2} / \mathbf{d f}$ & GFI & AGFI & IFI & NNFI & CFI & RMSEA \\
\hline Environmental values & 3.463 & 0.958 & 0.922 & 0.946 & 0.918 & 0.946 & 0.078 \\
Prosocial behavior & 2.787 & 0.965 & 0.935 & 0.971 & 0.956 & 0.971 & 0.066 \\
Sustainable behavior & 3.856 & 0.907 & 0.867 & 0.942 & 0.928 & 0.942 & 0.084 \\
\hline
\end{tabular}

According to Fornell and Larcker's [43] approach, the CR (Composite Reliability) value should be greater than 0.6, and Hair et al. [44] indicated that 0.7 was acceptable. Table 2 shows that the factor loadings of 32 items are all greater than 0.5 . The $C R$ values of each latent variable-less-polluting and help-are slightly less than 0.7 , and the rest are greater than 0.7. These results are acceptable. Fornell and Larcker [43] suggested that the AVE (Average Variance Extracted) should be greater than 0.5. The AVE values of the latent variables-less polluting and help-in this study are slightly less than 0.5 , and the rest all greater than 0.5 . The results of the whole model test show that the internal consistency and validity of dimensions in the model are acceptable.

Table 2. Summary of convergent validity results.

\begin{tabular}{ccccc}
\hline \multirow{2}{*}{ Latent Variables } & \multirow{2}{*}{ Observational Variables } & \multicolumn{3}{c}{ Convergent Validity } \\
\cline { 3 - 5 } & & Loading & CR & AVE \\
\hline Environmental values & & & & \\
\hline \multirow{2}{*}{ Recyclable } & A1 & 0.730 & 0.768 & 0.528 \\
& A2 & 0.813 & & \\
A3 & 0.624 & & 0.360 \\
Less polluting & A4 & 0.661 & 0.626 & \\
& A5 & 0.611 & & \\
\hline
\end{tabular}


Table 2. Cont.

\begin{tabular}{|c|c|c|c|c|}
\hline \multirow{2}{*}{ Latent Variables } & \multirow{2}{*}{ Observational Variables } & \multicolumn{3}{|c|}{ Convergent Validity } \\
\hline & & Loading & CR & AVE \\
\hline \multirow{3}{*}{ Resource saving } & A7 & 0.733 & 0.764 & 0.519 \\
\hline & A8 & 0.748 & & \\
\hline & A9 & 0.679 & & \\
\hline \multicolumn{5}{|l|}{ Prosocial behaviors } \\
\hline \multirow{3}{*}{ Care } & A10 & 0.767 & 0.795 & 0.564 \\
\hline & A11 & 0.731 & & \\
\hline & A12 & 0.755 & & \\
\hline \multirow{3}{*}{ Help } & A13 & 0.581 & 0.675 & 0.411 \\
\hline & A14 & 0.617 & & \\
\hline & A15 & 0.717 & & \\
\hline \multirow{3}{*}{ Understanding } & A16 & 0.795 & 0.790 & 0.557 \\
\hline & A17 & 0.723 & & \\
\hline & A18 & 0.718 & & \\
\hline \multicolumn{5}{|l|}{ Sustainable behaviors } \\
\hline \multirow{3}{*}{ Resale } & A19 & 0.508 & 0.854 & 0.676 \\
\hline & $\mathrm{A} 20$ & 0.967 & & \\
\hline & A21 & 0.913 & & \\
\hline \multirow{4}{*}{ Donation } & $\mathrm{A} 22$ & 0.829 & 0.890 & 0.670 \\
\hline & A23 & 0.866 & & \\
\hline & $\mathrm{A} 24$ & 0.811 & & \\
\hline & A25 & 0.763 & & \\
\hline \multirow{7}{*}{ Reuse } & A26 & 0.751 & 0.919 & 0.615 \\
\hline & A27 & 0.784 & & \\
\hline & A28 & 0.806 & & \\
\hline & A29 & 0.822 & & \\
\hline & A30 & 0.826 & & \\
\hline & A31 & 0.801 & & \\
\hline & A32 & 0.691 & & \\
\hline
\end{tabular}

\subsection{Results}

There were a total of 407 participants in this study. A total of $33.7 \%$ of the participants were male and $66.3 \%$ were female; $51.6 \%$ were undergraduates and $48.4 \%$ postgraduates. The average age was 25.18 years, and ages ranged from 18 to 58 years.

Hypotheses 1 and 4: Regarding the influence of environmental values and prosocial behavior on resale, this study ran a residual correlation according to the modification index. Table 3 shows that the GFI, AGFI, IFI, NNFI and CFI values are 0.972, 0.94, 0.982, 0.969 and 0.982, respectively, and those are considered a good fit. The RMSEA value is 0.062 , which is acceptable. The value of the chi-square/df ratio is 2.574 , which conforms to the standard. Consequently, the model fit of resale is acceptable. The results of the t-test reveal that the influence of environmental values on resale is insignificantly different from zero $(\beta=0.139, p>0.05)$. This means that environmental values are not a significant factor influencing consumers' choices regarding clothing resale. The results of the t-test reveal that the influence of prosocial behavior on resale is significantly different from zero $(\beta=-2.031, p<0.05)$, with a negative parameter. This means that prosocial behavior is a significant factor influencing consumers' resale of clothing; however, the greater an individual's alignment with prosocial behavior, the less willing they will be to sustainably resell clothing. Consequently, hypothesis 1 is not supported and hypothesis 5 is supported. Table 4 provides a summary of these items.

Hypotheses 2 and 5: Regarding the influence of environmental values and prosocial behavior on clothing donation, this study ran a residual correlation according to the modification index. Table 3 
shows that the GFI, AGFI, IFI, NNFI and CFI values are $0.929,0.869,0.952,0.928$ and 0.952 , respectively, and those are considered to be acceptable. The RMSEA value is 0.096 , which shows a slightly greater than good fit. The value of the chi-square/df ratio is 4.728 , which is acceptable. Consequently, the model fit of donation is acceptable. The results of the $t$-test reveal that the influence of environmental values on donation is significantly different from zero $(\beta=0.263, p<0.01)$, with a positive parameter. This means that environmental values are a significant factor influencing consumers' donation of clothing. The results of the $t$-test reveal that the influence of prosocial behavior on donation is significantly different from zero $(\beta=0.521, p<0.01)$, with a positive parameter. This means that prosocial behavior is a significant factor influencing consumers' choices regarding clothing donation. The results show that the more environmental values and prosocial behavior a consumer displays, the more they will be willing to sustainably donate their clothing. Consequently, both Hypothesis 2 and Hypothesis 5 are supported. Table 4 provides a summary of these items.

Hypotheses 3 and 6: Regarding the influence of environmental values and prosocial behavior on clothing reuse, this study ran a residual correlation according to the modification index. Table 3 shows that the GFI, AGFI, IFI, NNFI and CFI values are 0.93, 0.892, 0.955, 0.941 and 0.955, respectively, and those are considered to be acceptable. The RMSEA value is 0.075 , and that is considered acceptable. The value of chi-square/df ratio is 3.29, which is acceptable. Consequently, the model fit of reuse is acceptable. The results of the t-test reveal that the influence of environmental values on reuse is insignificantly different from zero $(\beta=0.129, p>0.05)$. This means that environmental values are not a significant factor influencing consumers' reuse of clothing. The results of the t-test reveal that the influence of prosocial behavior on reuse is insignificantly different from zero ( $\beta=-0.083, p>0.05)$. This means that prosocial behavior is not a significant factor in consumers' choices to reuse clothing. Consequently, both Hypothesis 3 and Hypothesis 6 are not supported. Table 4 provides a summary of these items.

Table 3. Summary of model fit for sustainable clothing disposal.

\begin{tabular}{cccccccc}
\hline Models & $\boldsymbol{\chi}^{\mathbf{2}} / \mathbf{d f}$ & GFI & AGFI & IFI & NNFI & CFI & RMSEA \\
\hline Resale & 2.574 & 0.972 & 0.94 & 0.982 & 0.969 & 0.982 & 0.062 \\
Donation & 4.728 & 0.929 & 0.869 & 0.952 & 0.928 & 0.952 & 0.096 \\
Reuse & 3.29 & 0.93 & 0.892 & 0.955 & 0.941 & 0.955 & 0.075 \\
\hline
\end{tabular}

Table 4. Summary of parameter estimation from the influential factors-environmental values and prosocial behavior-on consumers' sustainable clothing disposal behavior.

\begin{tabular}{|c|c|c|c|c|c|}
\hline \multirow{2}{*}{ Paths } & \multicolumn{2}{|c|}{ Unstandardized Coefficients } & \multirow{2}{*}{$\beta$} & \multirow{2}{*}{$t$-Value } & \multirow{2}{*}{$p$-Value } \\
\hline & B & S.E. & & & \\
\hline Resale $<-$ Environmental values & 0.319 & 0.272 & 0.139 & 1.175 & 0.24 \\
\hline Resale $<$-Prosocial behavior & -0.507 & 0.25 & -0.234 & $-2.031 *$ & 0.042 \\
\hline Donation $<$-Environmental values & 0.425 & 0.162 & 0.263 & $2.624^{* *}$ & 0.009 \\
\hline Donation $<-$ Prosocial behavior & 0.788 & 0.152 & 0.521 & $5.178^{* * *}$ & 0.000 \\
\hline Reuse $<-$ Environmental values & 0.323 & 0.403 & 0.129 & 0.8 & 0.423 \\
\hline Reuse $<-$ Prosocial behavior & -0.184 & 0.347 & -0.083 & -0.532 & 0.595 \\
\hline
\end{tabular}

${ }^{*} p<0.05,{ }^{* *} p<0.01,{ }^{* * *} p<0.001$

\subsection{Discussion}

For Hypotheses 1 and 4, environmental values did not influence consumers' willingness to resell clothing. The results related to environmental values were not consistent with previous research in which undergraduate resale behaviors were related to environmental issues [9]. However, prosocial behavior was associated with the tendency to resell clothing, but negatively. The more alignment with prosocial behavior, the more consumers are unwilling to resell clothing; in other words, prosocial consumers will use other patterns to dispose of their clothing. The results regarding prosocial 
behavior were similar to previous research—female consumers in South Africa indicated that their least selected method for the disposal of unwanted apparel is resale [36]. Another study also indicated that resale is not the most common option for handling home textiles [20]. The differences in the results of this study may be related to differences in times, cultures or participant growth backgrounds in the past, such as clothes' short-term usage due to poor material, which has caused an increase in discarded clothing [38], or due to cheaper new products today. Traditionally, Chinese society emphasized diligence and thriftiness and advocated cultivating virtues that would enable one to maintain a moral character. To resell clothes can not only display thriftiness but can also display respect for the environment and society, yet this study found that few participants resell clothes. Perhaps prosocial consumers think other patterns would demonstrate more care, help and understanding than resale. Additionally, perhaps other factors such as resale price, secondhand shop availability or access to online markets were more influential than environmental values-the actual problems were more important than the values.

Regarding Hypotheses 2 and 5, environmental values and prosocial behavior influenced consumers' willingness to donate clothes. The results were consistent with previous research-consumers' environmental consciousness was related to donation behavior [9,23]. Additionally, the results were consistent with another survey study, which found that compassion was related to sustainable purchase criteria [33]. Another study also revealed that the philanthropic factor positively influences sustainable consumption behavior [32]. The same study also found that donation was the most used method, which was consistent with another study from overseas [20,34]. In sum, waste reduction and concern for others are related to clothing donation. Donating goods and materials to a demander is perhaps a universal value, whether in Eastern culture or Western culture, or by age or gender. Consumers generally accept donating clothes; sharing clothes with people may reflect Chinese values to treasure the sources and prosocial experiences such as love for people or helping others. Moreover, convenience is one of the popular reasons for donation [20].

For Hypotheses 3 and 6, both environmental values and prosocial behavior did not influence consumers' willingness to reuse clothing. The results of this study were not consistent with interview results in previous research, which found that consumers repurposed old clothes with their crafting skills in consideration of environmental protection [21]. Furthermore, the results were not consistent with prior research, which revealed that prosocial behavior was associated with the tendency to reuse clothing [28]. Research indicated that reuse is not the most common option for handling home textiles [20]. According to results in this study, participants exhibited a low willingness to reuse clothing. Compared to females in the past, today's females are not interested in sewing. For consumers who are willing to reuse instead of discard clothing, there may be other more influential factors than environmental values and prosocial behavior. These consumers may consider practical aspects, such as their interest in clothing alternation, craft skills or thrifting. The Chinese tradition is to manage household affairs by being industrious and thrifty; in the past, old clothes were used over and over again, especially in hard times. Emulation of such behavior in modern times could stop environmental pollution in the garment production process and display care toward society.

Figure 2 reveals that the influence of prosocial behavior on clothing resale is consistent with the hypothesis of behaviorism theory. Figure 2 shows that both environmental values' and prosocial behavior's influence on consumers' willingness to donate their clothing is consistent with behaviorism as well. Figure 2 indicates that the non-influence of the two factors on consumers' reusing behavior is not consistent with the hypothesis. Donation is the most ordinary model among the three models, because of protecting the environment and caring for others. However, the results did reveal that the reuse model is not accepted by consumers. Disposal of new clothes directly rather than reusing old clothes is more likely to be accepted. As for the resale model, the prosocial reason of caring for others has caused consumers to consider other choices such as donations to be more valuable; on the other hand, the economic factor may be more attractive than environmental values for resale. In sum, consumers' clothing disposal is still influenced by discarding old clothes and buying new ones. 
The study results represent a test application of the behaviorism theory model, which can be used to analyze the influence factors of sustainable clothing disposal. To face clothing waste issues, one can intensify traditional values of industriousness and thriftiness, and of compassion and sympathy to others, to accelerate the promotion of the sustainable disposal of clothing.

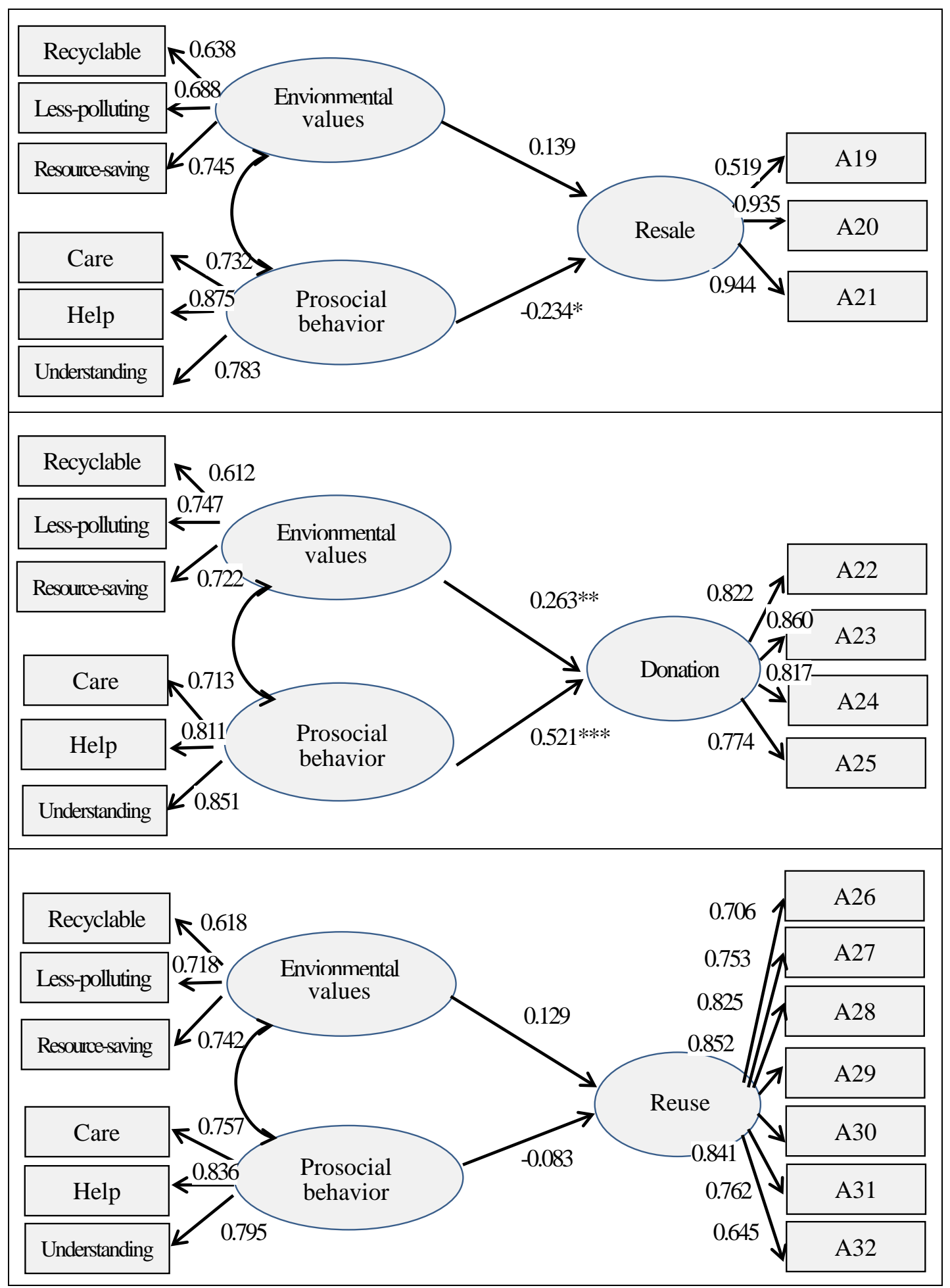

${ }^{*} p<0.05,{ }^{* *} p<0.01,{ }^{* * *} p<0.001$.

Figure 2. (Top) Model of resale framework. (Middle) Model of donation framework. (Bottom) Model of reuse framework. 


\section{Conclusions}

The behaviorism theory model is effective in analyzing the factors influencing sustainable clothing disposal. Consumers' clothing donation behavior was influenced by the factors of environmental values and prosocial behavior. Clothing resale was influenced by the factor of prosocial behavior. However, prosocial consumers used other disposal patterns instead of resale. Clothing reuse was not influenced by either environmental values or prosocial behavior. Further discussion concerning resale is necessary. Research indicated that the choice of sustainable disposal mainly relates to environmental concerns, disposal convenience and economic reasons, as prosocial behavior plays a lesser role [20].

This study suggests that consumers could choose to purchase high-quality and value-added products that are more durable and more sustainable, so that they do not need to make frequent repurchases, save expenses and reduce waste. To face today's environmental requirements, the values of "love the people", "love all things", "respect for nature" and "thriftiness" from traditional instruction play a decisive role.

On the other hand, this study found that consumers showed a low willingness toward resale or reusing clothing. Government and private enterprise, such as clothing companies or clothes recycling companies, strategies include cooperation [34], expanding and enhancing environmental education programs, systematic construction of multiple channels, expanding the clothes recycling market, offering clothing rental and consultation services, organizing DIY classes, promoting clothes exchange and alternation or other economic feedbacks. Since multi-channels provide convenience to consumers and can satisfy them with different requirements, perhaps they can also raise consumers' willingness to participate in the practice of circular products. Further, prolonging the clothing durability, incorporating design aesthetics, improving after-sales services and advocating garment recycling could enhance the general acceptance of sustainable clothing disposal [38] and maximize the effectiveness of the after-sales management of clothes, which is the most important goal.

As the data collection in this study was limited to Taiwan, the clothing disposal behavior of consumers in other countries is not presented herein. It is necessary to conduct a multinational survey in order to create generality of the survey results. Moreover, multinational analysis and comparison are beneficial to the exchange of ideas and further exploration of related issues.

Further, the sample was limited to undergraduates and postgraduates, so it did not compare different ages to understand differences in clothing disposal behavior and its influencing factors in different generations of consumers. Further discussion for future research is required.

Additionally, this study used a quantitative survey, but it could understand more about the potential reasons and influential factors behind sustainable disposal if it integrated a qualitative methodology and selected some of the participants to participate in in-depth interviews. Based on the results, the public sector can plan and manage efficient methods for clothing disposal, such as universal regional offices to receive different types of used clothing, simple processes and a simple online platform. The most important thing is to reduce resource consumption and prevent discarded clothes from going into a landfill or incinerator.

Author Contributions: C.-E.C. has made substantial contributions to the conception and design, acquisition of data and analysis and interpretation of data. C.-C.L. was involved in drafting the manuscript and revising it critically for important intellectual content. All authors have read and agreed to the published version of the manuscript.

Funding: This research received no external funding.

Conflicts of Interest: The authors declare no conflict of interest.

\section{References}

1. Peng, H.-C. 438 Pieces of Clothing Are Discarded Per Minute in TAIWAN. Available online: https://www.gvm. com.tw/article.html?id=41699 (accessed on 16 July 2019).

2. Fu, H.-Y. Prosocial Behavior Affect the Intention to Energy Saving and Carbon Reduction Action: A Perspective of the Theory of Planned Behavior. Ph.D. Thesis, National Taiwan Normal University, Taipei, Taiwan, 2015. 
3. Watson, J.B. Psychology as the behaviorist views it. Psycho. Rev. 1913, 20, 158-177. [CrossRef]

4. Cheunga, M.F.Y.; To, W.M. An extended model of value-attitude-behavior to explain Chinese consumers' green purchase behavior. J. Retail. Consum. Serv. 2019, 50, 145-153. [CrossRef]

5. Putri, P.A.S.; Srimulyo, K. The effects of social media use on the increase of the quality of learning and teaching activities at senior high school. J. Talent Dev. Excell. 2020, 12, 261-266.

6. Jung, S.; Jin, B. Sustainable development of slow fashion businesses: Customer value approach. Sustainability 2016, 8, 540. [CrossRef]

7. Rana, S.; Pichandi, S.; Karunamoorthy, S.; Bhattacharyya, A.; Parveen, S.; Fangueiro, R. Carbon footprint of textile and clothing products. In Handbook of Sustainable Apparel Production; CRC Press: Boca Raton, FL, USA, 2015; pp. 141-166. ISBN 978-1482299373. Available online: https://books.google.com.tw/ books?hl= zh-TW\&lr=\&id=-TGsCQAAQBAJ\&oi=fnd\&pg=PP1\&dq=Handbook+of + Sustainable + Apparel+ Production \&ots=QyJtwOmc3R\&sig=moqeBIQjQemKQzNub7T1Y7FMtss\&redir_esc=y\#v=onepage\&q= Handbook\%20of\%20Sustainable\%20Apparel\%20Production\&f=false (accessed on 21 February 2020).

8. United Nations World Commission on Environment and Development (WCED) Our Common Future Report. 1987. Available online: https://www.encyclopedia.com/environment/energy-government-and-defensemagazines /united-nations-world-commission-environment-and-development-wced-our-common-futurereport-1987 (accessed on 20 July 2019).

9. Joung, H.-M.; Park-Poaps, H. Factors motivating and influencing clothing disposal behaviours. Int. J. Consum. Stud. 2011, 37, 105-111. [CrossRef]

10. Bianchi, C.; Birtwistle, G. Consumer clothing disposal behavior: A comparative study. Int. J. Consum. Stud. 2012, 36, 335-341. [CrossRef]

11. Weber, S.; Lynes, J.; Young, S.B. Fashion interest as a driver for consumer textile waste management: Reuse, recycle or disposal. Int. J. Consum. Stud. 2016, 41, 207-215. [CrossRef]

12. Suar, D.; Khuntia, R. Influence of personal values and value congruence on unethical practices and work behavior. J. Bus. Ethics 2010, 97, 443-460. [CrossRef]

13. Skinner, B.F. About Behaviorism; Knopf Doubleday Publishing Group: New York, NY, USA, 1976; pp. 163-183. ISBN 0-394-71618-3. Available online: https://books.google.com.tw/books?hl=zh-TW\&lr=\&id=K7WKkwPzNqsC\&oi= fnd\&pg=PA3\&dq=About+behaviorism\&ots=3h_Nk2Chvd\&sig=oxe5obwpKYQb8jDMY-JhESqtVnY \&redir _ $\mathrm{esc}=\mathrm{y} \# \mathrm{v}=$ onepage $\& \mathrm{q}=\mathrm{About} \% 20$ behaviorism\&f=false (accessed on 22 February 2020).

14. Dominicis, S.D.; Schultz, P.W.; Bonaiuto, M. Protecting the environment for self-interested reasons: Altruism is not the only pathway to sustainability. Front. Psychol. 2017, 8, 1065. [CrossRef]

15. Mondal, P. The Meaning and Functions of Social Values. Available online: https://www.yourarticlelibrary. com/sociology/the-meaning-and-functions-of-social-values-sociology/8522 (accessed on 23 July 2019).

16. Schwartz, S.H.; Bilsky, W. Toward a universal psychological structure of human values. J. Pers. Soc. Psychol. 1987, 53, 550-562. [CrossRef]

17. Speth, J.G.; Martin, G.T. The Bridge at the Edge of the World: Capitalism, the Environment, and Crossing from Crisis to Sustainability; Yale University Press: New Haven, CT, USA, 2008; Available online: http://rachel.org/?q=es/node/ 6956/print (accessed on 10 March 2020).

18. Li, J.; Ai, W. Examining environmental protection by the thought of the unity of heaven and man. Environ. Dev. 2018, 3, 209-211.

19. Shim, S. Environmentalism and consumers' clothing disposal patterns: An exploratory study. Cloth. Text. Res. J. 1995, 13, 38-48. [CrossRef]

20. Lehner, M.; Mont, O.; Mariani, G.; Mundaca, L. Circular economy in home textiles: Motivations of IKEA consumers in Sweden. Sustainability 2020, 12, 5030. [CrossRef]

21. Paras, M.K.; Ekwall, D.; Pal, R.; Curteza, A.; Chen, Y.; Wang, L. An exploratory study of Swedish charities to develop a model for the reuse-based clothing value chain. Sustainability 2018, 10, 1176. [CrossRef]

22. Bukhari, M.A.; Carrasco-Gallego, R.; Ponce-Cueto, E. Developing a national programme for textiles and clothing recovery. Waste Manag. Res. 2018, 36, 321-331. [CrossRef]

23. Morgan, L.R.; Birtwistle, G. An investigation of young fashion consumers' disposal habits. Int. J. Consum. Stud. 2009, 33, 190-198. [CrossRef]

24. Jones, E.E.; Colman, A.M. Social psychology. In The Social Science Encyclopedia, 2nd ed.; Kuper, A., Kuper, J., Eds.; Routledge: London, UK, 1996; pp. 797-800. ISBN 0-415-10829-2. Available online: https://scholar.google.com.tw/ scholar?hl=zh-TW\&as_sdt=0\%2C5\&q=Social+psychology\&btnG= (accessed on 25 February 2020). 
25. Graziano, W.G.; Eisenberg, N. Agreeableness: A dimension of personality. In Handbook of Personality Psychology; Academic Press: Cambridge, MA, USA, 1997; pp. 795-824. ISBN 978-0121346454.

26. Midgett, C.; Bendickson, J.S.; Muldoon, J.; Solomon, S.J. The sharing economy and sustainability: A case for Airbnb. Small Bus. Inst. J. 2017, 13, 51-71. [CrossRef]

27. Shah, R.; Pillai, P. Consumer's environmental concern \& its influence on their purchase intention: SEM Approach. Int. J. Manag. 2012, 2, 24-31.

28. Cruz-Cárdenas, J.; Guadalupe-Lanas, J.; Velín-Fárez, M. Consumer value creation through clothing reuse: A mixed methods approach to determining influential factors. J. Bus. Res. 2019, 101, 846-853. [CrossRef]

29. Gwozdz, W.; Nielsen, K.S.; Müller, T. An environmental perspective on clothing consumption: Consumer segments and their behavioral patterns. Sustainability 2017, 9, 762. [CrossRef]

30. Morais, C.; Montagna, G. Customized wardrobe: Clothing according to user. Procedia Manuf. 2015, 3, 5814-5821. [CrossRef]

31. Domina, T.; Koch, K. Consumer reuse and recycling of post-consumer textile waste. J. Fash. Mark. Manag. Int. J. 1999, 3, 346-359. [CrossRef]

32. Hwang, Y.Y.; Jo, G.Y.; Oh, M.J. The persuasive effect of competence and warmth on clothing sustainable consumption: The moderating role of consumer knowledge and social embeddedness. Sustainability 2020, 12, 2661. [CrossRef]

33. Geiger, S.M.; Keller, J. Shopping for clothes and sensitivity to the suffering of others: The role of compassion and values in sustainable fashion consumption. Environ. Behav. 2018, 50, 1119-1144. [CrossRef]

34. Norum, P.S. Trash, charity, and secondhand stores: An empirical analysis of clothing disposition. Fam. Consum. Sci. Res. J. 2015, 44, 21-36. [CrossRef]

35. Koch, K.; Domina, T. Consumer textile recycling as a means of solid waste reduction. Fam. Consum. Sci. Res. J. 2009, 28, 3-17. [CrossRef]

36. Sonnenebrg, N.C.; Marx-Pienaar, J.M.M.; Stols, M.J. Female consumer's apparel disposal behaviour in the South African emerging market context. Waste Manag. Environ. 2019, 231, 281-285. [CrossRef]

37. Carlo, G.; Randall, B.A. The development of a measure of prosocial behaviors for late adolescents. J. Youth Adolesc. 2002, 3, 31-44. [CrossRef]

38. Niinimäki, K.; Hassi, L. Emerging design strategies in sustainable production and consumption of textiles and clothing. J. Clean. Prod. 2011, 19, 1876-1883. [CrossRef]

39. Kerlinger, F.N.; Lee, H.B. Foundations of Behavioral Research, 4th ed.; Wadsworth Publishing: Marceline, MO, USA, 2000; pp. 163-190. ISBN 0-15-507897-6. Available online: https:/www.semanticscholar.org/ paper/\%E0\%B8\%9A\%E0\%B8\%97\%E0\%B8\%A7\%E0\%B8\%B4\%E0\%B8\%88\%E0\%B8\%B2\%E0\%B8\%A3\%E0 $\%$ B8 $\% 93 \%$ E0\%B9\%8C\%E0\%B8\%AB \%E0\%B8\%99\%E0\%B8\%B1\%E0\%B8\%87\%E0\%B8\%AA \%E0\%B8\%B7 \%E0\%B8\%AD-\%22Foundations-of-Behavioral-The-By-\%E0\%B8\%9E\%E0\%B8\%B1\%E0\%B8\%99\%E0\% B8\%98\%E0\%B8\%B8\%E0\%B8\%A1\%E0\%B8\%99\%E0\%B8\%B2\%E0\%B8\%A7\%E0\%B8\%B4\%E0\%B8\%99/ 6e29ee2617666451edf1a2a43786d3fb68ff21b1?p2df (accessed on 7 March 2020).

40. Nunnally, J.C. Psychometric Theory-25 Years Ago and Now. Educ. Res. 1975, 4, 7-21. [CrossRef]

41. Browne, M.W.; Cudeck, R. Alternative ways of assessing model fit. Sociol. Methods Res. 1992, 21, $230-258$. [CrossRef]

42. Bagozzi, R.P.; Yi, Y. On the evaluation for structural equation models. J. Acad. Mark. Sci. 1988, 16, 74-94. [CrossRef]

43. Fornell, C.; Larcker, D.F. Evaluating structural equation models with unobservable variables and measurement error. J. Mark. Res. 1981, 18, 39-50. [CrossRef]

44. Hair, J.F.; Black, W.C.; Babin, B.J.; Anderson, R.E. Multivariate Data Analysis, 5th ed.; Prentice Hall College Div.: Upper Saddle River, NJ, USA, 1998; pp. 91-150. ISBN 978-0138948580. Available online: https:// pdfs.semanticscholar.org/6885/bb9a29e8a5804a71bf5b6e813f2f966269bc.pdf (accessed on 11 March 2020).

Publisher's Note: MDPI stays neutral with regard to jurisdictional claims in published maps and institutional affiliations. 